\title{
A INEFICÁCIA DAS MEDIDAS PENAIS BRASILEIRAS EM RELAÇÃO À PSICOPATIA: O Distanciamento entre o Psicopata e a Sociedade
}

\author{
http://dx.doi.org/10.21527/2176-6622.2021.56.12046
}

Recebido em: 12/2/2021

Modificações solicitadas em: 5/4/2021

Aceito em: 19/4/2021

Juliana Castro Torres

Autora correspondente. Universidade do Estado de Minas Gerais (UEMG) - Unidade Passos. Av. Juca Stockler, no 1130 - Bairro Belo Horizonte. Passos/MG, Brasil. CEP 37900-106. http://lattes.cnpq.br/4486423547641606. https://orcid.org/0000-0001-9094-4715. jucastrotorres@hotmail.com

Jessica Cristina de Moraes Universidade do Estado de Minas Gerais (UEMG) - Unidade Passos. Passos/MG, Brasil.

Zaíra Garcia de Oliveira Universidade do Estado de Minas Gerais (UEMG) - Unidade Passos. Passos/MG, Brasil.

\section{RESUMO}

Objetiva o presente artigo compor análise do alcance da responsabilidade penal do psicopata considerando as ramificações da culpabilidade na condição de ser imputável, semi-imputável ou inimputável. Para tanto, a pesquisa deu-se em duas mãos, a primeira com a análise das características psicológicas do indivíduo identificado como psicopata, bem como a realização do incidente de insanidade mental e medidas de segurança a serem aplicadas em eventual condenação, enfatizando a importância do exame pericial. Já a segunda deu-se com a análise das leis e jurisprudências brasileiras acerca da responsabilidade penal do psicopata. Desse modo, concluiu-se que o estudo do tema "psicopatia" é extremamente exíguo no campo doutrinário e na construção legislativa, fator que, sem dúvidas, resulta na impossibilidade da devida aplicação da responsabilidade penal àqueles diagnosticados com este transtorno de personalidade. Isso porque, o que se observa é que sequer magistrados deliberam de forma uníssona em julgamentos que tratam de casos afetos a psicopatas. A metodologia da pesquisa foi baseada na pesquisa descritiva, procedimentos bibliográficos e método hipotético-dedutivo.

Palavras-chave: Psicopatia; culpabilidade; responsabilidade penal.

\section{THE INEFFECTIVENESS OF BRAZILIAN CRIMINAL MEASURES IN RELATION TO PSYCHOPATHY: THE DISTANCING BETWEEN PSYCHOPATH AND SOCIETY}

\section{ABSTRACT}

This article aims to make an analysis of the scope of criminal liability of a psychopath considering the ramifications of the culpability while being imputable, semi-imputable or non-imputable. Therefore, the research was divided in two parts, the first one with the analysis of the psychological characteristics of the individual identified as a psychopath, as well as the implementation of the incident of mental insanity and security measures to be applied in a possible conviction, emphasizing the importance of an expert inspection. And, the second one, occurred with the analysis of the Brazilian laws and jurisprudence regarding the criminal liability of a psychopath. This time, it was concluded that the study of the theme "psychopathy" is extremely small in the doctrinal field and in the making of laws for the legislative, a factor that, without a doubt, results in the impossibility of the proper application of criminal liability to those diagnosed with this personality disorder. This is because, what is observed is that even magistrates deliberate unanimously in trials that deal with cases related to psychopaths. The methodology of this research was based on descriptive research, bibliographic procedures, hypothetical-deductive method.

Keywords: Psychopathy; culpability; criminal liability. 


\section{INTRODUÇÃO}

O conhecimento da mente psicopata desperta atenção dos mais curiosos e constitui tema cativante de discussão na esfera penal, contudo muito ainda há por ser descoberto para a perfeita compreensão das motivações que levam alguém a delinquir, notadamente em se tratando de ato ilícito contra a vida e contra a liberdade sexual, os quais, preponderantemente, são os mais praticados por psicopatas.

Nessa lógica, cabe pontuar que fatores biológicos, como a personalidade, e fatores sociais, como a conjuntura socioeconômica na qual o indivíduo está inserido, podem agravar ou atenuar a conduta criminosa, uma vez que o crime é um reflexo social.

Com efeito, considerando a necessidade de o Direito Penal preencher a lacuna de informações relativas ao quebra-cabeças que envolve a psicopatia, surge na criminologia a possibilidade de que, compreendendo o delinquente quando do seu comportamento e do contexto no qual o crime foi executado, o estudo do crime e dos pormenores que levaram ao seu cometimento sejam analisados a fim de satisfatória aplicação da lei penal.

Veja-se: Se muitas vezes a figura do psicopata não é compreendida e tratada como o que de fato é, como poderiam os magistrados ter plena consciência e capacidade técnica suficiente para julgar e, em sendo o caso, condenar psicopatas? É daí que surge a incapacidade penal brasileira de aplicar o Direito no caso em concreto, posto que não há consenso, ou sequer entendimento, da persona do psicopata. Não se sabe, ou ao menos não se deliberou, se o psicopata se trata de imputável, semi-imputável ou inimputável.

À vista disso, no intuito de trazer resposta à problemática, este artigo objetiva avaliar como o psicopata é visto juridicamente para que, somente então, possa ser dada a resposta penal condizente com a sua condição de entender e de se determinar de acordo com esse entendimento. Isto é, sendo o psicopata inimputável, semi-imputável ou imputável, qual medida de pena (pena privativa de liberdade ou medida de segurança) faz jus à sua conduta delituosa e melhor assegura a paz social?

Nessa linha intelectiva, ressalta-se que a essência do artigo é discutir sobre a persona do psicopata em relação ao Judiciário quando do seu reconhecimento como criminoso e da aplicação da pena, vez que se trata de tema pouco debatido tanto no meio acadêmico quanto no meio legislativo.

Noutro giro, a pesquisa foi concluída em duas etapas. Num primeiro momento aborda-se a análise do perfil do psicopata, quando será discutida sua origem e características, bem como da competência de julgamento que o psicopata possui na modulação de seus atos sobre a conduta socialmente aceita. Cuida-se, em seguida, do estudo das medidas de segurança aplicáveis e da necessidade do exame pericial ou incidente de insanidade mental, para que, enfim, adentremos no cerne da pesquisa, explorando a responsabilidade penal do psicopata, apresentando, inclusive, possíveis respostas do Direito Penal de acordo com a culpabilidade, estrutura da punição e entendimento de tribunais brasileiros (jurisprudência e projetos de lei).

O tema foi construído a partir da observação de lacunas no amparo penal da aplicação e execução da pena para psicopatas. Nisto, questiona-se: A ineficácia da responsabilidade penal é ocasionada pela falta de medidas legislativas ou de fato inexiste responsabilidade penal suficiente para conter os males da psicopatia?

Por derradeiro, a metodologia da pesquisa foi baseada na pesquisa descritiva, procedimentos bibliográficos e método hipotético-dedutivo.

\section{A CLASSIFICAÇÃO DA PSICOPATIA NA HISTÓRIA E NO DIREITO PENAL SOB O RECORTE DO DISTANCIAMENTO ENTRE O PSICOPATA E A SOCIEDADE}

Conhecedores da morbidade e da curiosidade que o tema da psicopatia desperta na sociedade, muitos meios tendem a equiparar psicopatas com assassinos em série ou outros tipos de criminosos desalmados e cruéis, sem que se reúnam, no entanto, os traços de personalidade do verdadeiro psicopata, isso porque, "a problemática conceitual do uso indevido do termo se relaciona com outra questão, o diagnóstico da psicopatia" (GARRIDO, 2009, p. 85, tradução nossa).

No campo científico, a primeira menção do transtorno de personalidade foi realizada pelo médico francês Philippe Pinel que, em 1809, cunhou o termo "mania sem delírio" ou "manie sans delire" - sujeito insano 
(manie) com sequer nenhuma confusão mental (sans delire). À época, o sujeito insano sem confusão mental servia de sinônimo para classificar o indivíduo que agia pura e somente de acordo com seus instintos.

Nesse contexto, Pinel foi precursor ao constatar que determinados pacientes que se envolviam em atos autodestrutivos e impulsivos possuíam a aptidão de raciocínio imaculada, tendo até mesmo consciência da incongruência de seus atos.

Mais à frente, no início do século 20, Emil Kraepelin acreditava que a personalidade psicopática seria diferente da psicose, pois, "a personalidade psicopática trata-se de graus anteriores da psicose, sendo composta por personalidades afetadas por influências hereditárias desfavoráveis, por lesões germinativas (ou cerebrais) ou, ainda, por outras inibições precoces" (ANDRADE, 1996, p. 22-23, tradução nossa). Nessa seara, em razão de seus atributos psicológicos, ou, da falta deles, seriam as personalidades psicopáticas ligadas a comportamentos antissociais, distinguindo-se em quatro tipos de sujeitos.

O primeiro grupo seria composto por enganadores e trapaceiros mórbidos, simpáticos e cativantes, embora não apresentassem moralidade e empatia para com os demais. O segundo seria composto por criminosos que agem sem pensar e não têm controle volitivo, envolvendo-se em pequenas transgressões. $O$ seguinte grupo seria composto por criminosos especializados, que apresentam muita educação e são comumente benquistos pela sociedade, mas que, em verdade, são nada além de manipuladores egoístas. E, por último, o quarto grupo seria composto por "boêmios vagabundos que conduzem seus dias sem quaisquer responsabilidades, à mercê da vadiagem" (MILLON; SIMONSEN; BIRKET-SMITH, 1998. p. 10, tradução nossa).

O que se constata é que o termo "psicopatia" tem história longa e variada, remontando a centenas de anos, já tendo sido, inclusive, sinônimo de condutas sociais reprováveis e doenças da mente.

Ocorre que, atualmente, a psicopatia traduz-se em uma forma de especificar o transtorno da personalidade antissocial, prevalente em indivíduos que cometem uma variedade de atos criminosos e geralmente se comportam de forma irresponsável.

Nas palavras de Guilherme de Souza Nucci (2020, p. 404-405), "as personalidades antissociais não excluem a culpabilidade por não afetar a inteligência". Em verdade, é encontrada em indivíduos com capacidade intelectiva pouco afetada, conquanto com personalidade notadamente inclinada à delinquência, pois é caracterizada pela indiferença e desrespeito pelo contrato social.

Em resumo, somada a personalidade antissocial com a inclinação à delinquência, são os psicopatas incapazes de entender culpa e, por isso, incapazes de ressocialização, sobretudo na hipótese de esta ser oferecida por meio da punição ou sanção penal, quando, recorrentemente, os psicopatas tendem a proteger a si próprios, atribuindo a culpa a terceiros ou até mesmo encontrando meios para justificar seus atos (GATTAZ, 1999).

Sob o mesmo recorte da personalidade antissocial, Hervey Cleckley explica que os psicopatas não pertencem à classe dos impreterivelmente transgressores, mas, sim, ao nicho de pessoas que são, entre outros fatores, impulsivos, charmosos e possuem emoções rasas e inexistência de sentimento de culpa, podendo, inclusive, tornarem-se empresários, físicos, cientistas e políticos. Nessa linha, existem psicopatas primários e secundários, que se subdividem em descontrolados e carismáticos:

Os Psicopatas Primários: não respondem ao castigo, à apreensão, à tensão e nem à desaprovação. Parecem ser capazes de inibir seus impulsos antissociais quase todo o tempo, não devido à consciência, mas sim porque isso atende ao seu propósito naquele momento. As palavras parecem não ter o mesmo significado para eles que têm para nós. Não têm nenhum projeto de vida e parecem ser incapazes de experimentar qualquer tipo de emoção genuína. Os Psicopatas Secundários: são arriscados, mas são indivíduos mais propensos a reagir frente a situações de estresse, são beligerantes e propensos ao sentimento de culpa. Os psicopatas desse tipo se expõem a situações mais estressantes do que uma pessoa comum, mas são tão vulneráveis ao estresse como a pessoa comum. São pessoas ousadas, aventureiras e pouco convencionais, que começaram a estabelecer suas próprias regras do jogo desde cedo. São fortemente conduzidos por um desejo de escapar ou de evitar a dor, mas também são incapazes de resistir à tentação. Tanto os psicopatas primários como os secundários estão subdivididos em: Psicopatas Descontrolados: são os que parecem se aborrecer ou enlouquecer mais facilmente e com mais freqüência do que outros subtipos. Seu delírio se assemelhará a um ataque de epilepsia. Em geral, também são homens com impulsos sexuais incrivelmente fortes, capazes de façanhas assombrosas 
com sua energia sexual. Também parecem estar caracterizados por desejos muito fortes, com vício em drogas, a cleptomania, a pedofilia ou qualquer tipo de indulgência ilícita ou legal. Psicopatas Carismáticos: são mentirosos, encantadores e atraentes. Em geral, são dotados de um ou outro talento e o utilizam a seu favor para manipular os outros. São geralmente compradores e possuem uma capacidade quase demoníaca de persuadir os outros a abandonarem tudo o que possuem, inclusive suas vidas. Com freqüência, esse subtipo chega a acreditar em suas próprias invenções. São irresistíveis (CLECKLEY, 1988, tradução nossa).

Por derradeiro, cabe ainda trazer à tona a definição de psicopata apontada pela médica psiquiátrica brasileira Ana Beatriz Barbosa Silva (2008, p. 32). Para ela, os psicopatas seriam indivíduos que usam da frieza, falta de escrúpulos, dissimulação, mentiras e sedução para lograr êxito próprio, ou seja, dada a incapacidade de estabelecer vínculos afetivos ou empatia, a culpa e remorso são afastados para dar lugar a comportamentos extremamente individualistas, em maior ou menor escala.

Nessa linha, os psicopatas seriam predadores sociais encontrados em qualquer meio social, visto que os traços de psicopatia podem estar presentes em executivos, líderes religiosos, trabalhadores comuns, pais e mães de família e políticos, com a diferença de um para os outros sendo apenas o grau de psicopatia, pois que, enquanto uns expressam a violência de forma direta e visível a olho nu quando do cometimento de homicídios, outros expressam a violência na corrupção, na manipulação de massas ou do seio familiar.

Em outras palavras, psicopata seria o indivíduo que, pela falta de emoções e empatia para com seus pares e costumes sociais, delinque sem arrependimento, sendo, inclusive, incapaz de reparação. Isso significa que, pela falta intensiva de responsabilidade, arrependimento e cuidado empático para com os demais, os psicopatas são carentes de emoções, e, por isso, indiferentes tanto às regras sociais e quanto à sociedade em si.

Com efeito, o Direito Penal brasileiro, no intuito de possibilitar a identificação dos psicopatas, inseriu nos ritos processuais o incidente de insanidade mental quando há dúvida fundada sobre a integridade mental do acusado - fundada por que não se faz suficiente para o exame médico-legal requerimento injustificado ou fundado em meras suposições (REIS; GONÇALVES, 2018, p. 253), o que significa dizer que a produção de provas periciais não se dá ao arbítrio de qualquer dos componentes do jogo processual, seja vítima, acusado ou magistrado, mas sim em razão do juízo de relevância e pertinência por parte de seu destinatário.

Sob o atento olhar de Renato Brasileiro de Lima (2017, p. 1.191-1.192), a aferição do estado de saúde mental do acusado é fundamental para definir se o indivíduo é imputável e, a partir daí, decidir o rito do procedimento penal a ser adotado. Isso porque duas são as hipóteses em caso de instabilidade da saúde mental do acusado: se, ao tempo dos fatos, era o acusado incapaz, mister é o reconhecimento da sua inimputabilidade, com consequente imposição de medida de segurança em razão da absolvição imprópria; e, se acometido por disfunções mentais somente durante o curso do processo, a persecução deve ser suspensa até o reestabelecimento das faculdades mentais do acusado.

O que significa que não basta saber da doença mental do acusado, seja ela total ou parcial. Importa, em verdade, aferir se em razão da doença ou desenvolvimento incompleto ou retardado o acusado não possuía à época dos fatos capacidade cognitiva e volitiva suficientes para entender e autodeterminar-se de acordo com esse entendimento (LIMA, 2017, p. 1.192).

Em outras palavras, concerne à pesquisa responder se a higidez mental do investigado afetou ou não o ato ilícito praticado para que no decorrer do processo penal a análise das conclusões do incidente de insanidade corrobore as respostas dadas pelo Direito Penal, a fim de que seja averiguado se o investigado possuía ou não à época dos fatos capacidade cognitiva de discernimento, total ou parcial, dos atos.

Amoldando-se à análise do presente artigo, insta trazer à baila a jurisprudência nacional que, de forma não unânime, decide como será a responsabilidade penal dos indivíduos classificados como "psicopatas". Vejamos.

APELAÇÃO CRIMINAL - DELITOS DE AMEAÇA E INCÊNDIO - ARTIGOS 147 E 250, INC. II, ALÍNEA 'a', AMBOS DO CÓDIGO PENAL - AUTORIA E MATERIALIDADE COMPROVADAS - RÉU INIMPUTÁVEL - MEDIDA DE SEGURANÇA INTERNAÇÃO - SUBSTITUIÇÃO PARA TRATAMENTO AMBULATORIAL - IMPOSSIBILIDADE - EVIDÊNCIAS DE PERICULOSIDADE DO ACUSADO - RECURSO NÃO PROVIDO. - Na aplicação da medida de segurança deve o julgador observar a natureza do crime cometido, o potencial de periculosidade do réu e o grau da psicopatia, ainda que 
A INEFICÁCIA DAS MEDIDAS PENAIS BRASILEIRAS EM RELAÇÃO À PSICOPATIA:

O DISTANCIAMENTO ENTRE O PSICOPATA E A SOCIEDADE

Juliana Castro Torres - Jessica Cristina de Moraes - Zaíra Garcia de Oliveira

o crime seja apenado com reclusão. - Diante das evidências de periculosidade do réu, justifica-se submetê-lo à medida de segurança de internação (TJ-MG - APR: 10428130027223001 MG, Relator: Jaubert Carneiro Jaques, Data de Julgamento: 08/11/2016, Câmaras Criminais/6ạ Câmara Criminal, Data de Publicação: 22/11/2016).

APELAÇÃO CRIMINAL. HOMICÍDIO QUALIFICADO CONSUMADO E HOMICÍDIO QUALIFICADO TENTADO. ALEGAÇÃO DE VEREDICTO MANIFESTAMENTE CONTRÁRIO À PROVA DOS AUTOS. NÃO RECONHECIMENTO DA SEMI-IMPUTABILIDADE PELOS JURADOS. RÉU DIAGNOSTICADO COMO PSICOPATA. IRRELEVÂNCIA. EXISTÊNCIA DE LAUDO PSIQUIÁTRICO INDICANDO QUE O RÉU TINHA CAPACIDADES COGNITIVA E VOLITIVA PRESERVADAS. VEREDICTO DOS JURADOS AMPARADOS EM PROVA CONSTANTE DOS AUTOS. VEREDICTO MANTIDO. 1 . A doutrina da psiquiatria forense é uníssona no sentido de que, a despeito de padecer de um transtorno de personalidade, o psicopata é inteiramente capaz de entender o caráter ilícito de sua conduta (capacidade cognitiva). 2. Amparados em laudo psiquiátrico atestando que o réu possuía, ao tempo da infração, a capacidade de entendimento (capacidade cognitiva) e a capacidade de autodeterminar-se diante da situação (capacidade volitiva) preservadas, os jurados refutaram a tese da semi-imputabilidade, reconhecendo que o réu era imputável. 3. Não merece qualquer censura a sentença proferida pelo Presidente do Tribunal do Júri que deixou de reduzir a reprimenda pela causa prevista no art. 26, parágrafo único, do Código Penal, se o soberano conselho de sentença não afastou a tese da semi-imputabilidade do réu. (AP 5004417-64.2012.827.0000, Rel. Juíza da 1ạ Câmara Criminal, julgado em 10/02/2015).

Nota-se que a culpabilidade dos psicopatas transita, para a jurisprudência, entre a semi-imputabilidade e imputabilidade, visto que, se, de um lado, uns entendem que a depender do grau de psicopatia do réu deve ser imputada a medida de segurança, de outro, entende-se que o psicopata é imputável, tendo em sua personalidade um viés de entendimento malévolo e hostil, com comportamento antissocial destrutivo e com elevada tendência à reincidência delitiva.

É nesse cenário que vem à tona o distanciamento entre o psicopata e a sociedade, uma vez que, sendo inconteste que os psicopatas possuem maior racionalidade se comparado ao homem médio, não sofrendo, portanto, de psicoses e delírios, e que são ótimos manipuladores, capazes de articular situações com perfeição para obter logro próprio, tudo em razão de deficiência de empatia, resta perguntar: Como um ser sem capacidade de sentir emoções poderia moldar seu comportamento para atender às expectativas sociais?

Certo é que o psicopata possui capacidade de entendimento ou capacidade cognitiva, no entanto, considerando a pouca capacidade de se controlar e se autodeterminar diante da situação, como se justifica a imputação de pena inteira àquele que possui capacidade volitiva reduzida e encontra-se à mercê de impulsos primitivos?

Na esfera da tipicidade e da ilicitude não há o que se discutir, visto que se amoldando a conduta ao tipo penal, não há dúvidas quanto à tipicidade e quanto à ilicitude, vez que "o juízo de ilicitude é posterior e dependente do juízo de tipicidade, de forma que todo fato penalmente ilícito também é, necessariamente, típico" (MASSON, 2020, p. 376) e vice-versa.

Em sendo, contudo, a culpabilidade o juízo de censura, ou, nas palavras de Masson (2020, p. 376) "o juízo de reprovabilidade que incide sobre a formação e a exteriorização da vontade do responsável por um fato típico e ilícito, com propósito de aferir a necessidade de imposição de pena", repisa-se: Como uma pessoa incapaz de sentir emoções poderá entender o juízo de reprovação social, comportando-se de forma moral e socialmente aceita se com isto não se importa?

Sendo a personalidade do psicopata irremediavelmente predisposta à criminalidade e a comportamentos estranhos aos que a sociedade tem por padrão, não se pode esperar que uma pessoa sem consciência se amolde aos ditames sociais e jurídicos conhecidos e seguidos pelos demais integrantes da sociedade, visto que não se trata de indivíduo comum.

Exemplificando, suponhamos que determinado indivíduo, por razões que pouco importam, não possui a capacidade de ouvir melodias musicais e ouve apenas a letra, como na declamação de um poema. Na sequência, suponhamos o mesmo indivíduo em um evento social no qual se faz necessária a dança, conquanto para o referido indivíduo, e somente para ele, não há melodia, todas as músicas tornaram-se somente textos corridos. Nesse cenário, qual é o comportamento esperado do indivíduo? Como ele se comportaria? Iria dançar 
sem nenhuma música? Pois seria o mesmo que dançar lendo ou ouvindo a declamação de um poema. Ou, iria o indivíduo conter-se, por, para ele, não fazer sentido dançar sem melodia?

O socialmente esperado é que para o homem médio, ou seja, indivíduo sem qualquer dano cerebral e conhecedor dos costumes sociais, dançar sem melodia faria total sentido pela força do contrato social, uma vez que o indivíduo em questão se importaria com o juízo de reprovabilidade e, por isso, dançaria até mesmo sem ouvir melodia, tudo em razão de manter o contrato social e não gerar contra si reprovabilidade, pois é isto que mantém a sociedade ordenada, o pacto social assinado tacitamente por todos os que o compreendem.

Estando, no entanto, a falta de melodia para a falta de entendimento e respeito pelas normas sociais, como no caso do psicopata, como exigir a conduta social esperada de alguém que não entende e não respeita condutas sociais?

É exatamente por serem situações que somente quem as experiencia consegue de fato alcançar que o Direito Penal brasileiro é falho. Isso em razão de que a medida da régua observada pelos legisladores e pelos magistrados não é a medida da régua do psicopata, mas sim a do homem médio.

Em se tratando de casos cometidos por psicopatas, o viés adotado não é a aplicação do Direito Penal ao caso em concreto, pois se o fosse dificilmente seriam os psicopatas julgados e condenados pelo mesmo tipo e rigor das leis comuns direcionadas ao homem comum. Em verdade, o que se apresenta nos julgamentos é a medida da régua da equiparação, uma vez que o psicopata é visto em pé de igualdade, no tocante à sua capacidade volitiva e cognitiva, com os demais indivíduos da sociedade. Fatores que não poderiam gerar outro produto que não a ineficiência da legislação penal nos casos de psicopatia, uma vez que não pode ser ressocializado aquele que não se importa ou tampouco quer fazer parte da sociedade.

Por esse ângulo, Ana Beatriz Barbosa Silva (2008) comenta:

Nos países em que isso está muito bem organizado (Austrália, Inglaterra, Canadá), os psicopatas, além de serem tratados com todo o rigor da lei, são separados dos demais. Eles são minoria no sistema penitenciário, totalizam em média $20 \%$, enquanto os criminosos não psicopatas, os que têm algum grau de sentimento, totalizam em média $80 \%$. Então, o que se faz? Você trabalha aquele que pode ser recuperado, você não mistura. $E$ se eles forem do tipo muito predador - que seriam aqueles que têm um caso mais grave e que têm prazer em ver sangue; quando não basta matar, tem que matar e esquartejar - eles são postos em celas separadas para o resto da vida. Por que? Porque são animais selvagens (...) que não podem ser recuperados.

É dizer que não basta o amparo social ou penal, pois os psicopatas não são pessoas passíveis de recuperação, uma vez que demonstrada a deficiência de empatia e arrependimento. É dizer que ainda que classificado como imputável, semi-imputável ou inimputável, não há o que se fazer, pois não há recuperação para aqueles que não se amoldam aos costumes sociais.

\section{O DEBATE ACERCA DA (IN)IMPUTABILIDADE DO PSICOPATA}

Sabe-se que o Direito Penal visa à proteção de bens considerados indispensáveis à coexistência social, visto que a mácula do direito à vida, à liberdade, à honra e à propriedade acarreta consequências jurídicas que podem, no caso mais gravoso, trazer consigo o ônus da perda da liberdade. Assim, o Direito Penal é o "campo jurídico que, utilizado em última ratio, determina o que é crime, estabelece penas e prevê medidas restritivas de direito ou liberdade, que podem ser aplicadas aos agentes infratores das normas" (GRECO, 2017, p. 4).

Dito isto, como funciona a imputabilidade dos psicopatas quando da (in)imputabilidade?

Para tanto, pouco importa o mérito dos indivíduos que, muito embora sejam psicopatas, somente prejudicam as pessoas de maneiras diversas sem o cometimento de crimes, pois o Direito não se ocupa de aplicar medidas para fatos não tipificáveis.

Como já elucidado, o Código Penal prevê no artigo 26 que "é isento de pena o agente que, por doença mental ou desenvolvimento mental incompleto ou retardado, era, ao tempo da ação ou da omissão, inteiramente incapaz de entender o caráter ilícito do fato ou de determinar-se de acordo com esse entendimento" (BRASIL, 1940). Nesse contexto, se a psicopatia não é lida como doença mental, já estaria descartada a inimputabilidade prevista no caput do artigo 26 . Em se tratando, todavia, da semi-imputabilidade prevista no pa- 
A INEFICÁCIA DAS MEDIDAS PENAIS BRASILEIRAS EM RELAÇÃO À PSICOPATIA:

O DISTANCIAMENTO ENTRE O PSICOPATA E A SOCIEDADE

Juliana Castro Torres - Jessica Cristina de Moraes - Zaira Garcia de Oliveira

rágrafo único do mesmo artigo, observa-se que a psicopatia pode ser entendida como perturbação da saúde mental, cabendo, neste caso, questionamentos acerca da capacidade volitiva e cognitiva daquele que praticou o ilícito penal.

Nesse recorte, o principal entendimento doutrinário é de que "a psicopatia, por si só, não leva à inimputabilidade do agente" (ZARLENGA, 2000, p. 484, tradução nossa). Por sua vez, os doutrinadores que pensam ser inimputáveis os psicopatas, visto que não possuem capacidade de compreender a antijuridicidade de uma ação e de determinar-se conforme o entendimento, acreditam que

os psicopatas, as personalidades psicopáticas, os portadores de neuroses profundas, etc., em geral têm capacidade de entendimento e determinação, embora não plena. Estão na mesma categoria legal que os que possuem o desenvolvimento mental incompleto, mas que atingiram certo grau de capacidade psíquica de entendimento e autodeterminação de acordo com as regras sociais [silvícolas em aculturação, surdos-mudos em processo de instrução], etc. Por fim, incluem-se os agentes com desenvolvimento mental retardado, que nas faixas mais elevadas têm alguma capacidade de entendimento e autodeterminação. Em todas as hipóteses, comprovadas por exame pericial, o agente será condenado, mas, tendo em vista a menor reprovabilidade de sua conduta, terá sua pena reduzida entre um e dois terços, conforme o artigo 26, parágrafo único (MIRABETE, 1999, p. 224).

No mesmo sentido, Garrido (2009, p. 117, tradução nossa) entende que "os psicopatas compreendem a ilicitude de seus atos, e, em ato contínuo, atuam conforme tal conhecimento. A capacidade intelectual e volitiva destes sujeitos está intacta", sendo, neste caso, contraproducente isentar de pena o psicopata, visto que para o afastamento da culpabilidade com consequente isenção de pena, deve restar clara a incompreensão da ilicitude da ação e da impossibilidade de agir de acordo com este entendimento.

Em sentido contrário, Zaffaroni (in COVELLI, 2009) acredita que o psicopata não pode ser considerado imputável, pois a soma da sua conduta antissocial e do seu comportamento agressivo à reincidência da delinquência, apenas denotam a falta de importância que o psicopata atribui às consequências dos seus atos, sejam consequências de ordem moral, como a reprovação social, ou consequências de cunho penal, como a imposição de pena.

Nessa hipótese, o que se faz necessário não é a imputação de pena privativa de liberdade, sim a de medida de segurança, internando o psicopata em local apropriado para que receba o devido tratamento.

Logo, considerando o entendimento da doutrina majoritária, acredita-se que boa parte dos apenados psicopatas tenham sido condenados com parâmetros análogos aos usados para condenação de delinquentes comuns. Isso porque, considerando que o Código Penal não faz distinção entre este e aquele, não há que se falar em tratamento diferenciado, sendo psicopatas e delinquentes de baixa periculosidade encarcerados em prisões comuns, quiçá na mesma cela, se considerarmos o abarrotamento das prisões brasileiras.

Da leitura do Código Penal brasileiro, tendo em vista que nem a doutrina, nem os tribunais são pacíficos a respeito da (in)imputabilidade do psicopata, a única conduta diversa do encarceramento conjunto de apenados de baixa e grave periculosidade seria a adoção do artigo 59 do referido Código, visto que ali reside margem para aumento da pena-base na primeira fase da dosimetria da pena. Ou seja, se considerada a conduta social, a personalidade do agente, os motivos, as circunstâncias e consequências do crime, pode o juiz aumentar (ou diminuir) as penas aplicáveis entre as cominadas e a quantidade de pena aplicável, dentro dos limites previstos. É o que preceituam os incisos I e II do artigo 59 do Código Penal.

Nessa lógica, ainda que o crime de um psicopata tenha sido perfeitamente correspondente a um crime de um sujeito comum, a pena daquele seria elevada no mínimo legal, no que tange à sua personalidade, a título de punição.

O que se percebe é que não há consenso nenhum acerca da classificação psicológica do psicopata. Muito pouco foi estudado e muito pouco é entendido e debatido sobre o tema, logo, impossível seria classificar o psicopata quanto à sua culpabilidade, posto que até mesmo o incidente de insanidade mental é pouco utilizado e, reitera-se, não há consenso sobre o grau de imputabilidade do psicopata. 


\section{Direito Debate}

A INEFICÁCIA DAS MEDIDAS PENAIS BRASILEIRAS EM RELAÇÃO À PSICOPATIA:

O DISTANCIAMENTO ENTRE O PSICOPATA E A SOCIEDADE

Juliana Castro Torres - Jessica Cristina de Moraes - Zaíra Garcia de Oliveira

Ao passo que o psicopata está afastado dos olhos da legislação vigente tanto quanto da classificação da sua (in)imputabilidade, não há caminho certo e determinado a ser traçado pelo Judiciário na aplicação da sanção, o que, decerto, abre margem para medidas insuficientes na execução da pena.

\section{A RESPONSABILIDADE PENAL DO PSICOPATA NOS TRIBUNAIS BRASILEIROS}

Como já esclarecido, não há concordância entre doutrina e magistrados, ou, tampouco, entre magistrados e magistrados, visto que não há um único norte para o julgamento dos casos que envolvem psicopatia.

Isso se dá porque, costumeiramente, os termos "psicopatas" ou "psicopatia" são usados muitas vezes erroneamente, seja por ignorância das vítimas, testemunhas ou até mesmo do próprio autor do ato delituoso quando da referência a outros e a si mesmo como "psicopatas" meramente para acentuar o seu comportamento transgressor, observando-se que poucos são os casos que, efetivamente, contêm alcance técnico quando pesquisadas as palavras-chave "psicopatia" e "psicopata" nos julgamentos dos tribunais brasileiros.

Da consulta a cada tribunal criminal estadual brasileiro usando as palavras-chave antes mencionadas, aferiu-se que a esmagadora maioria de resultados retorna o uso das palavras como forma de descrever a personalidade dos acusados sem qualquer embasamento técnico, como forma de pseudônimo ou até mesmo como meio de infligir pena ou medo, o que significa que os casos nos quais de fato foi realizado algum exame clínico suficiente para o diagnóstico de patologias psíquicas, seja da psicopatia ou da personalidade antissocial, são escassos no ordenamento jurídico brasileiro.

Afirmativa que se confirma, eis que, da busca nos 27 Tribunais de Justiça estadual existentes no Brasil, apenas 6 apresentaram resultados com a presença do termo técnico envolvendo as palavras "psicopata" e "psicopatia", perfazendo um total de 10 processos em todas as plataformas usadas para práticas jurídicas por via de processos judiciais eletrônicos.

Os dois primeiros resultados foram encontrados no Tribunal de Justiça de Alagoas, em que o termo "psicopata" surge no relatório do magistrado, que esclarece que o apelante alega ser acometido por patologia psíquica - psicopatia ou personalidade dissocial - que o torna inimputável. Respaldado, no entanto, por laudo pericial que embora reconheça a patologia (epilepsia) e transtorno de personalidade dissocial do apelante, repisa o magistrado que os transtornos mentais não impedem que seja (o apelante) responsabilizado pelos seus atos, devendo ser aplicada medida de internação hospitalar (Número do Processo: 002932017.2000.8.02.0050; Relator (a): Des. José Carlos Malta Marques; Comarca: Foro de Igreja Nova; Órgão julgador: Câmara Criminal; Data do julgamento: N/A; Data de registro: N/A).

No segundo resultado consta que a recorrente-ré foi submetida a laudo psiquiátrico que constatou perturbação de sua saúde mental, sendo ela plenamente capaz de entender o caráter ilícito do fato, incorrendo na personalidade psicopática, de modo a não possibilitar acolhimento de recurso para reparos na decisão de pronúncia (Número do Processo: 0026290-14.2006.8.02.0001; Relator (a): Des. Sebastião Costa Filho; Comarca: Foro de Maceió; Órgão julgador: Câmara Criminal; Data do julgamento: 14/11/2014; Data de registro: 21/11/2014).

O terceiro e o quarto resultados foram apurados no Tribunal de Justiça do Mato Grosso do Sul, no qual consta que o acusado de homicídio, estupro e corrupção de menores foi considerado psicopata por laudo pericial (TJMS. Apelação Criminal n. 0008611-73.2017.8.12.0021, Três Lagoas, 2a Câmara Criminal, Relator (a): Des. Ruy Celso Barbosa Florence, j: 31/07/2020, p: 07/08/2020) e que em agravo de execução penal proposto para o fim de progressão de regime, o qual foi indeferido em razão de laudo pericial que atestou que "o sentenciado é acometido pelo Transtorno de Personalidade Antissocial, cujos critérios diagnósticos (...) também podem ser conhecidos como psicopatia" (TJMS. Agravo de Execução Penal n. 0009379-85.2019.8.12.0002, Dourados, 2a Câmara Criminal, Relator (a): Juiz Waldir Marques, j: 05/09/2019, p: 06/09/2019).

No Tribunal de Justiça do Paraná foram encontrados o quinto e o sexto resultados. No primeiro, em que pese o réu possuir laudo atestando sua psicopatia, o entendimento do magistrado foi no sentido de que a patologia não acomete o raciocínio lógico, inexistindo, portanto, prova cabal de inimputabilidade (Processo: 0022673-31.2018.8.16.0035; Órgão Julgador: 1a Câmara Criminal; Data Julgamento: 25/07/2020). 
A INEFICÁCIA DAS MEDIDAS PENAIS BRASILEIRAS EM RELAÇÃO À PSICOPATIA:

O DISTANCIAMENTO ENTRE O PSICOPATA E A SOCIEDADE

Juliana Castro Torres - Jessica Cristina de Moraes - Zaíra Garcia de Oliveira

O resultado seguinte, na mesma inteligência, emprega o termo "psicopatia" para desmistificar as características do acusado, isso porque, consta que

o acusado não é portador de doença mental ou de perturbação da saúde mental, e que, apesar das características apontarem distúrbios em sua personalidade (traços de psicopatia), ele tinha total consciência e compreensão dos atos que praticava, detendo capacidade de planejamento e execução (Processo: 001880252.2015.8.16.0017; Órgão Julgador: 1a Câmara Criminal; Data Julgamento: 07/02/2019).

O sétimo resultado foi constatado no Tribunal de Justiça do Piauí, quando o termo "psicopatia" foi empregado para esclarecer que da

análise da conduta social, entendida como comportamento em qualquer meio social, ou seja, familiar, profissional, na vizinhança, etc., e a personalidade do agente, compreendida como o retrato psíquico do agente com prevalência ou não dos valores negativos, tais como inveja, prazer no sofrimento alheio, ânsia pela satisfação imediata dos desejos, psicopatias, e outras características que tornam uma personalidade voltada para o crime, podem sim agregar elementos individualizadores na dosimetria da pena (TJPI - APC 070192318.2018.8.18.0000; Relator (a): Joaquim Dias de Santana Filho, Data de julgamento 05/09/2018).

O oitavo resultado foi encontrado no Tribunal de Justiça de Santa Catarina, quando o magistrado profere sentença asseverando "não preencher o pressuposto subjetivo o apenado que não apresenta uma perspectiva de melhorar sua vida, assim como possui características de psicopatia e pedofilia, evidenciando um alto risco de reincidência criminal" (TJSC, Recurso de Agravo n. 2013.031180-0, de Joinville, rel. Roberto Lucas Pacheco, Quarta Câmara Criminal, j. 01-08-2013).

Por fim, os dois últimos resultados foram colhidos no Tribunal de Justiça do Tocantins, no qual consta pedido de progressão de regime negado em razão da carência de requisito subjetivo, visto que o réu foi diagnosticado como sociopata e psicopata por exame criminológico (EP 5007848-72.2013.827.0000, Rel. Juíza convocada Adelina Gurak, 5a Turma da 1a Câmara Criminal, julgado em 15/06/2016) e o caso de homicídio qualificado do qual se extrai que "a doutrina da psiquiatria forense é uníssona no sentido de que, a despeito de padecer de um transtorno de personalidade, o psicopata é inteiramente capaz de entender o caráter ilícito de sua conduta (capacidade cognitiva)" (AP 5004417-64.2012.827.0000, Rel. Juíza convocada Adelina Gurak, 5a Turma da 1a Câmara Criminal, julgado em 10/02/2015).

Isso posto, nota-se que nos tribunais estaduais raros são os casos em que há um lado pericial técnico, constatando-se que mesmo na hipótese de sua existência não há consenso entre a (in)imputabilidade do psicopata, uma vez que em cada canto do país o entendimento é pautado sob um aspecto diferente, seja no sentido reconhecer a inimputabilidade ou imputabilidade.

Vê-se que, se de um lado o entendimento é de que transtornos mentais não impedem a responsabilidade penal, de outro o entendimento é de que a análise da conduta social e da personalidade do agente devem agregar elementos individualizadores na dosimetria da pena, sendo suficientes, inclusive, para a aplicação da pena de medida de segurança.

\section{DA LEGISLAÇÃO CONCERNENTE AO CASO}

Pelo exposto, cediço que a falta de direcionamento legislativo em muito dificulta a aplicação do Direito nos casos que envolvem a psicopatia, uma vez que torna praticamente impossível que os magistrados decidam de forma uníssona, dado que a sua decisão deve conter amparo legal. Nesse recorte passa-se, então, às legislações que envolvem o tema da psicopatia.

Preliminarmente, insta destacar que o incidente de insanidade mental, prova pericial utilizada para concluir (ou não) ser o paciente acometido de psicopatia ou transtorno de personalidade antissocial, deve ser instaurado quando houver dúvida sobre a integridade mental do acusado, portanto não é todo pedido defensivo de instauração do incidente que justifica a sua realização, devendo o magistrado colher nos autos a existência de dúvida razoável sobre a sua sanidade. É o que prescreve o artigo 149 do Código de Processo Penal.

Nessa linha intelectiva, cumpre ainda reforçar que o incidente de insanidade mental não é medida obrigatória, caso não o quiser o paciente. Esclarece a jurisprudência pátria que 
A INEFICÁCIA DAS MEDIDAS PENAIS BRASILEIRAS EM RELAÇÃO À PSICOPATIA:

O DISTANCIAMENTO ENTRE O PSICOPATA E A SOCIEDADE

Juliana Castro Torres - Jessica Cristina de Moraes - Zaíra Garcia de Oliveira

ninguém é obrigado a fazer prova contra si próprio, como postula o princípio nemo tenetur se detegere, de modo que a paciente não pode ser obrigada a realizar o exame de insanidade mental contra a sua vontade (TJ-PR - HC: 14635484 - Curitiba - Rel.: José Maurício Pinto de Almeida - Unânime - J. 10.12.2015).

O acusado não é obrigado a comparecer ao exame de insanidade mental, pois, como desdobramento do princípio da não autoincriminação, pode se abster de produzir prova que seja contrária aos seus interesses no processo TJ-ES - APL 00003746120188080042, Relator: Sérgio Bizzotto Pessoa de Mendonça, Data de Julgamento: 17/07/2019, Segunda Câmara Criminal, Data de Publicação: 23/07/2019).

Ou seja, em não havendo nenhuma norma prevendo a obrigatoriedade de exames médicos para comprovar a psicopatia, ou até mesmo norma que regule a aplicabilidade da imputabilidade, semi-imputabilidade ou inimputabilidade nos mesmos casos, não há outro caminho para o magistrado decidir que não o da aplicabilidade da lei comum, isso porque inexiste qualquer ato normativo que mencione direta ou indiretamente no ordenamento jurídico brasileiro quais medidas devem ser adotadas, antes, durante ou depois do rito processual nos casos que envolvam psicopatas, sendo esta condição atestada ou não por incidente de insanidade mental.

Este é um fator que, pela via reflexa, reforça a assimetria das decisões judiciais, visto que o enquadramento do agente como psicopata depende de laudo, destacando-se que, em não havendo, não há que se falar em reconhecimento de inimputabilidade ou semi-imputabildiade, uma vez que não restará comprovada qualquer doença mental ou desenvolvimento mental incompleto ou retardado.

Cabe destacar, no entanto, em que pese a inexistência de norma regulamentadora, cumpre pontuar que foram propostas em plenário dois projetos de lei correlatos ao tema.

O primeiro, proposto pelo deputado federal Marcelo Itagiba, do partido Movimento Democrático Brasileiro - MDB - objetivou alterar a Lei de Execução Penal (Lei n. 7.210/84) para "criar comissão técnica independente da administração prisional e a execução da pena do condenando psicopata, estabelecendo a realização de exame criminológico do condenado à pena privativa de liberdade".

Se aprovado, o referido projeto de lei estabeleceria que o psicopata teria pena individualizada, cumprindo a pena em setor distinto daquele reservado aos demais presos, observando-se que a sua transferência para regime menos rigoroso, a concessão de livramento condicional, o indulto e a comutação de penas do condenado classificado como psicopata dependeria de laudo permissivo emitido por comissão técnica. Para tanto, justifica o deputado federal que a mudança deveria se dar porque:

No sistema carcerário brasileiro não existe um procedimento de diagnóstico para a psicopatia quando há solicitação de benefícios, redução de pena ou para julgar se o preso está apto a cumprir sua pena em regime semiaberto (...). Assim é que, acredito, a LEP deve ser alterada para que o programa individualizador da pena privativa de liberdade do condenado ou preso provisório classificado como psicopata vise ao restabelecimento do portador da psicopatia, sem descurar da recuperação dos demais presos. Para isso é preciso instrumentalizar o Estado com este fim, razão pela qual proponho a inclusão de §3 ao art. 84, para que o condenado ou preso provisório classificado como psicopata cumpra sua pena em seção distinta daquela reservada aos demais presos. De outro lado, é preciso também que a concessão de livramento condicional, o indulto e a comutação de penas do preso classificado como psicopata, bem como a sua transferência para regime menos rigoroso, dependa de laudo permissivo emitido por quem tenha condição técnica de fazê-lo, com a devida segurança, para que não aconteça fatos como o relatado por Ana Beatriz Barbosa Silva (op. cit): "Um caso que exemplifica a importância de medidas com as descritas acima é o de Francisco Costa Rocha, mais conhecido como "Chico Picadinho", autor de dois dos crimes de maior repercussão da história policial brasileira. Em 1966, Francisco, que até então parecia ser uma pessoa normal, matou e esquartejou a bailarina Margareth Suida em seu apartamento no centro de São Paulo. Chico foi condenado a 18 anos de reclusão por homicídio qualificado e mais dois anos e seis meses de prisão por destruição de cadáver. Em junho de 1974, oito anos depois de ter cometido o primeiro crime, Francisco foi libertado por bom comportamento. No parecer para concessão de liberdade condicional feito pelo então Instituto de Biotipologia Criminal constava que Francisco tinha "personalidade com distúrbio profundamente neurótico", excluindo o diagnóstico de personalidade psicopática. No dia 15 de outubro de 1976, Francisco matou Ângela de Souza da Silva com os mesmos requintes de crueldade e sadismo do seu crime anterior. Chico foi condenado a trinta anos de reclusão e permanece preso até hoje (ITAGIBA, 2010, p. 4-5). 


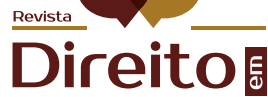 \\ Debate}

A INEFICÁCIA DAS MEDIDAS PENAIS BRASILEIRAS EM RELAÇÃO À PSICOPATIA:

O DISTANCIAMENTO ENTRE O PSICOPATA E A SOCIEDADE

Juliana Castro Torres - Jessica Cristina de Moraes - Zaíra Garcia de Oliveira

Ocorre que o projeto de lei anteriormente descrito foi arquivado por ser declarado prejudicial à aprovação do Projeto de Lei n.o 8.504/2017 que, dispondo sobre a progressão de regime de cumprimento de pena, apenas estabelece que, considerando também crime hediondo o crime de genocídio, o condenado por genocídio deverá cumprir a pena integralmente em regime fechado.

O segundo, proposto pelo deputado federal Carlos Lapa, do Partido Socialista Brasileiro, objetivava acrescentar ao inciso III, alterando parágrafo único do artigo 96 , bem como acrescentar parágrafo único ao artigo 97, ambos do Código Penal, para instituir medida de segurança nacional.

Se aprovada, a medida de segurança social perpétua seria acrescentada ao rol de medidas de segurança do artigo 96, do Código Penal Brasileiro, sendo que ainda que extinta a punibilidade, para o caso do psicopata, persistira a medida de segurança. Neste caso, a medida de segurança social perpétua seria

aplicada àquele, declarado, por junta médica, constituída de três psiquiatras oficiais, ser declarado psicopata, que cometer estupro ou atentado violento ao pudor, seguidos de morte contra criança ou adolescente; e matar, sequencialmente, cuja ação indique certa constância nos procedimentos, meios e fins, e praticar ações que causem terror e intranquilidade à população, como forma de protesto causando a morte de inocentes (LAPA, 2007, p. 1).

A justificativa encontrada pelo deputado é que, a uma, a Constituição Federal não veda medida de segurança social para indivíduos que matam em série ou praticam estupro ou atentado violento ao puder contra crianças; e, a duas, segundo médicos psiquiatras da clínica forense, "o psicopata é incorrigível e (...) devem ser recolhidos em casas de custódia indefinidamente por medida de segurança, por serem todos eles, em face da conduta que é disposicionalmente perversa, constitucionalmente sádico-desalmada" (LAPA, 2007, p. 5). Por isso, na linha de pensamento de Carlos Lapa, a proteção da sociedade contra indivíduos com o desvio de conduta conhecido por "psicopatia", que "têm cometido os crimes mais bárbaros que escandalizam o mundo, principalmente por que as suas vítimas geralmente são as mais indefesas, como mulheres e crianças" (LAPA, 2007, p. 2), a medida de segurança social perpétua é ação que se faz necessária.

O Projeto de Lei antes descrito consta em situação de arquivamento.

Por todo o exposto, salvo melhor juízo, fato é que os psicopatas não recebem a devida atenção doutrinária e legislativa do poder Judiciário brasileiro, o que torna impossível que indivíduos psicopatas recebem penas e tratamentos não só adequados, como também similares, razão pela qual as medidas penais se tornam inócuas, uma vez que podem ou não ser aplicadas.

Ademais, a junção dos fatores anteriormente delineados com a aplicação da lei penal vigente resta prejudicial ao julgamento e ao cumprimento de pena do psicopata ao passo que o coloca no mesmo patamar do homem médio e não se mostra capaz de efetivamente apresentar medidas de contenção para a psicopatia.

\section{CONSIDERAÇÕES FINAIS}

De início, cumpre ressaltar que as legislações que ousaram tratar do tema "psicopatia" foram descartadas. Aqui, não se entra no mérito se tais projetos de lei de fato seriam eficazes, ou mais, se cumpririam a finalidade proposta, a de penas que realmente protejam a sociedade e o psicopata de si próprio. Aqui, importa que no Brasil inexistem dispositivos legais que regulem a aplicação da pena ou possíveis medidas de contenção para aqueles diagnosticados com personalidade psicopata.

Nesse aspecto, resta claro que não existem leis específicas sobre o tema, limitando a análise ao Código Penal, notadamente acerca da inimputabilidade na avaliação da capacidade cognitiva ou mental e volitiva da hora do crime, isto a fim de que o agente infrator possa receber penalmente a medida que lhe é devida.

Assim, o artigo 26, caput e parágrafo único, do Código Penal, quando da tratativa da inimputabilidade do caput, e da semi-imputabilidade do parágrafo único, esclarecem o tratamento díspar entabulado para um e outro, visto que, em que pesem ambos estarem acometidos por doenças mentais à época dos fatos, impossibilitando que tivessem plena consciência dos seus atos para se determinarem de acordo com as condutas morais e jurídicas esperadas, cumpre ao juiz, se a conduta de fato se amoldar na descrição, aplicar medidas de segurança para o inimputável e redução de pena para o semi-imputável. 
Nessa lógica, considerando que, a uma, o tema em comento é ignorado tanto pelo processo criminal quanto pela execução da pena, e, a duas, que o entendimento doutrinário pouco se dedica a abordá-lo, é notável (e justificável) a carência de embasamento e decisões uníssonas de magistrados na deliberação de casos que envolvam psicopatas. Logo, os apenados com psicopatia não têm outra alternativa se não tornarem-se um detento comum, apenas mais um encarcerado em meio a tantos outros.

Ainda neste recorte, no que respeita à jurisprudência, resta evidente que os magistrados adotam posturas diametralmente opostas, isso porque, enquanto alguns se coadunam ao conceito de semi-imputável, aplicando medidas de segurança, outros preferem penas privativas de liberdades altíssimas, como se tal medida fosse suficiente para sanar o problema da periculosidade social do psicopata.

Desta forma, o que se conclui é que, no contexto jurídico brasileiro, o psicopata é quase que inexistente, visto que pouco se fala no ambiente acadêmico e pouco se importam os legisladores, razão pela qual estão os psicopatas aquém da responsabilidade social penal legislativa.

Assim, questiona-se: O problema está na falta de medidas legislativas ou de fato não há responsabilidade penal suficiente para conter os males da psicopatia?

Do exposto, o que se extrai é que o problema está na falta de medidas legislativas e na responsabilidade penal que, no Brasil, é ineficiente para conter os males da psicopatia.

Isso porque a falta de medidas legislativas está inexoravelmente ligada à irresponsabilidade do psicopata.

Veja-se, é sabido que não pode o magistrado inovar no julgamento, devendo ater-se à legislação vigente de tal modo que, em não havendo medida específica para o psicopata, não pode o juiz, ao seu bel-prazer, aplicar pena diferente, que não as trazidas no bojo do Código Penal.

Dessa forma, considerando que os crimes cometidos por psicopatas e aqui analisados, em sua maioria, são apenados com sanções de reclusão (homicídio, estupro, lesão corporal de natureza grave, entre outros), o magistrado encontra-se restrito à aplicação de pena privativa de liberdade, com eventual redução de pena nos moldes do parágrafo único do artigo 26 do Código Penal, ou de medida de segurança na hipótese de o condenado ser inimputável.

$\mathrm{Na}$ aplicação da pena privativa de liberdade o apenado psicopata seria encarado como criminoso ordinário que, por sua vez, cumpre pena para quitar suas contas com a sociedade e cruzar as portas do sistema carcerário ressocializado. Este, todavia, não é o caso do psicopata, pois fato é que psicopatas não só são incapazes de arrependimento, como também, quando soltos e liberados para o convívio social, possuem alto índice de reincidência.

Nessa lógica, sentido ainda menor faria considerar o psicopata semi-imputável, isso porque, se o cumprimento de pena completa não é capaz de gerar qualquer mudança no comportamento do psicopata, que bem faria reduzir a sua pena?

Assim, resta clara a ineficiência da pena privativa de liberdade.

Nesse contexto, quando da medida de segurança, é certo que esta não possui limite para duração, podendo o paciente internado permanecer sob o resguardo estatal enquanto perdurar sua periculosidade.

Ocorre, no entanto, que não há norte legislativo que indique ser o psicopata inimputável, cabendo, dessa forma, ao alvitre do magistrado, mediante incidente de insanidade mental - este que, repisa-se, não possui caráter obrigatório e, nos termos do artigo 182 do Código Penal, não vincula o juiz aceitá-lo ou rejeitá-lo, no todo ou em parte - determinar o cumprimento da medida de segurança.

Nessa linha intelectiva há que ressaltar que, conforme jurisprudência de todos os Estados brasileiros, não há harmonia nas decisões judiciais, vez que se uns consideram o psicopata imputável, outros o definem como semi-imputável.

Observa-se que, efetivamente, não há medidas no Código Penal suficientes para aplicação de qualquer medida sancionatória para o psicopata. A questão somente será elucidada quando a legislação não mais se quedar inerte e, de fato, adotar postura, seja no sentido da imputabilidade ou da inimputabilidade do psicopata. 


\section{Direitol \\ Debate}

\section{A INEFICÁCIA DAS MEDIDAS PENAIS BRASILEIRAS EM RELAÇÃO À PSICOPATIA: \\ O DISTANCIAMENTO ENTRE O PSICOPATA E A SOCIEDADE \\ Juliana Castro Torres - Jessica Cristina de Moraes - Zaíra Garcia de Oliveira}

\section{REFERÊNCIAS}

ANDRADE, José Antônio Garcia. Psiquiatria criminal y forense. Madrid: Centro de Estudos Ramon Areces, 1996.

BRASIL. Decreto-Lei 2.848, de 7 de dezembro de 1940 - Código Penal. Diário Oficial da União, Poder Legislativo, Brasília, DF. Disponível em: http://www.planalto.gov.br/ccivil_03/decreto-lei/Del2848compilado.htm. Acesso em: 12 ago. 2020.

CLECKLEY, Hervey Milton. The mask of sanity. 5. ed. St. Louis: Editora Mosby. 1988. Disponível em: http://www.quantumfuture.net/store/sanity_1.PdF. Acesso em: 5 ago. 2020.

COVELLI, Luciano Andres. La Psicopatia en la condena y en la ejecución de la pena privativa de libertad. Buenos Aires: Revista de Derecho Penal, 2009.

GARRIDO, Francisco José Sanchez. Fisionomia de la psicopatia - concepto, origen, causas y tratamento legal. 3. ed. Madrid: Revista de Derecho Penal y Criminologia, 2009.

GATTAZ, Wagner F. Violência e doença mental: fato ou ficção? Revista Brasileira de Psiquiatria, São Paulo, v. 21 , n. 4 , 1999.

GRECO, Rogério. Curso de Direito Penal: parte geral - volume 1. 19. ed. Niterói: Editora Impetus, 2017.

ITAGIBA, Marcelo. Projeto de Lei 6858/2010 - Altera a Lei no 7.210, de 1984, Lei de Execução Penal, para criar comissão técnica independente da administração prisional e a execução da pena do condenado psicopata, estabelecendo a realização de exame criminológico do condenado a pena privativa de liberdade, nas hipóteses que especifica. Disponível em: https://www.camara. leg.br/proposicoesWeb/prop_mostrarintegra?codteor=737111\&filename=PL+6858/2010. Acesso em: 16 ago. 2020.

LAPA, Carlos. Projeto de Lei 03/2007 - Acrescenta-se inciso III, altera parágrafo único do art. 96 e acrescenta parágrafo único ao art. 97, ambos do Código Penal, instituindo a medida de segurança nacional. Disponível em: https://www.camara.leg.br/ proposicoesWeb/prop_mostrarintegra?codteor=433883\&filename=PL+3/2007. Acesso em: 16 ago. 2020.

LIMA, Renato Brasileiro de. Código de Processo Penal comentado. 5. ed. Salvador: Juspodivm, 2017.

MASSON, Cleber. Direito Penal: parte geral (arts. 1ํ a 120). 14. ed. Rio de Janeiro: Editora Método. 2020. V. 1.

MILLON, Theodore; SIMONSEN, Erik; BIRKET-SMITH, Morten. Historical conceptions of psychopaty in the United States and Europe - Psychopathy: antissocial, criminal and violente behavior. Nova York: The Guilford Press, 1998.

MIRABETE, Julio Fabbrini. Código Penal interpretado. São Paulo: Atlas, 1999.

NUCCI, Guilherme de Souza. Manual do Direito Penal. 16. ed. Rio de Janeiro: Editora Forense, 2020.

REIS, Alexandre Cebrian Araújo; GONÇALVES, Victor Eduardo Rios. Direito Processual Penal esquematizado. 7. ed. São Paulo: Editora Saraiva, 2018.

SILVA, Ana Beatriz Barbosa. Mentes perigosas - o psicopata mora ao lado. 1. ed. Rio de Janeiro: Editora Fontanar, 2008.

SILVA, Ana Beatriz Barbosa. Psicopata sem censura. Pt.1/2. YouTube. 2008. Disponível em: https://www.youtube.com/watch?v=Sv98xU9QxYw. Acesso em: 14 ago. 2020.

ZARLENGA, Marcelo. Esteban. El psicopata perverso en la jurisprudencia argentina: una primera aproximación. 10. ed. Buenos Aires: Cuadernos de Doctrina y Jurisprudencia Penal, 2000. V. 6. 